\title{
European Society of Gastrointestinal Endoscopy (ESGE) Guideline: Prophylaxis of post-ERCP pancreatitis
}

Authors

Institutions
J.-M. Dumonceau' , A. Andriulli², J. Deviere ${ }^{3}$, A. Mariani ${ }^{4}$, J. Rigaux ${ }^{3}$, T. H. Baron ${ }^{5}$, P. A. Testoni ${ }^{4}$

Institutions are listed at the end of article. submitted 7 January 2010 accepted after revision 15 March 2010

\section{Bibliography}

Dol http://dx.doi.org/

$10.1055 / \mathrm{s}-0029-1244208$

Endoscopy 2010; 42:

503-515 @ Georg Thieme

Verlag KG Stuttgart · New York

ISSN 0013-726X

\section{Corresponding author}

J.-M. Dumonceau, MD, PhD

Division of Gastroenterology and Hepatology

Geneva University Hospitals

rue Micheli-du-Crest 24

1205 Geneva

Switzerland

Fax: $+41-22-3729366$

jmdumonceau@hotmail.com
Pancreatitis is the most common complication of endoscopic retrograde cholangiopancreatography (ERCP). Risk factors for post-ERCP pancreatitis (PEP) are both patient-related and procedurerelated. Identification of patients at high risk for PEP is important in order to target prophylactic measures. Prevention of PEP includes administra-

\section{Introduction $\nabla$}

Endoscopic retrograde cholangiopancreatography (ERCP) has become almost exclusively a therapeutic procedure. Of all the currently performed gastrointestinal endoscopic procedures it carries the highest complication rate. Complications of ERCP include pancreatitis, bleeding, cholangitis, cholecystitis, and perforation. Of these complications, post-ERCP pancreatitis (PEP) is the most frequent. It is most often clinically mild or moderate in severity but in about $10 \%$ of cases it is severe and potentially fatal. Patient-related and procedure-related risk factors for PEP are well defined. Recently, effective measures to prevent PEP have been identified, and include improvement in cannulation techniques as well as pharmacological and instrumental interventions.

The aim of the guideline is to provide a framework to caregivers to implement available methods to minimize the incidence and severity of PEP. The recommendations are not designed to be rigid and cannot replace clinical judgment.

\section{Methods}

\section{$\nabla$}

The European Society of Gastrointestinal Endoscopy (ESGE) commissioned this guideline which was then endorsed by its Governing Board. The method used to formulate the guideline is summarized as follows. In 2009 a preliminary literature search was performed by the corresponding author. Original papers were identified by a tion of nonsteroidal inflammatory drugs (NSAIDs), use of specific cannulation techniques, and placement of temporary pancreatic stents. The aim of this guideline commissioned by the European Society of Gastrointestinal Endoscopy (ESGE) is to provide practical, graded, recommendations for the prevention of PEP.

search of PubMed/MEDLINE, The Cochrane Library, Embase, and the internet, with search terms "ERCP" and "pancreatitis." Articles were first selected by title. Their relevance was then confirmed by review of the corresponding abstract. Publications in non-English languages and those whose content was considered irrelevant were excluded. This initial search focused on fully published prospective studies, particularly randomized controlled trials (RCTs), though retrospective analyses and case series were also included if they addressed topics not covered in the prospective studies. Additional articles were identified by manually searching the reference lists of retrieved papers. A summary of the search findings was presented to the ESGE Governing Board.

The commissioned authors met three times and subsequently developed the guideline and incorporated recommendations from the members of the Governing Board. In November 2009, the final draft was sent to all individual ESGE members. After incorporation of comments made by the individual ESGE members, the manuscript was then sent to the Editorial Board of the journal Endoscopy for critique and international peer review. The final wording of the guideline document was agreed upon by all of the authors.

\section{Categories of evidence}

The strength of the evidence used in this guideline was that recommended by the Scottish Intercollegiate Guidelines Network [1]. The ratings of levels of evidence are summarized below: 
1++ High quality meta-analyses, systematic reviews of RCTs, or RCTs with a very low risk of bias

1+ Well-conducted meta-analyses, systematic reviews of RCTs, or RCTs with a low risk of bias

1- Meta-analyses, systematic reviews, or RCTs with a high risk of bias

2++ High quality systematic reviews of case-control or cohort studies; high quality case-control or cohort studies with a very low risk of confounding, bias, or chance, and a high probability that the relationship is causal

2+ Well-conducted case-control or cohort studies with a low risk of confounding, bias, or chance, and a moderate probability that the relationship is causal

2- Case-control or cohort studies with a high risk of confounding, bias, or chance and a significant risk that the relationship is not causal

3 Non-analytic studies, e.g. case reports, case series

4 Expert opinion.

\section{Grading of recommendations}

Recommendations were based on the level of evidence presented in support and were graded accordingly [1]. This grading is summarized below:

A At least one meta-analysis, systematic review, or RCT rated as $1++$ and directly applicable to the target population; or a systematic review of RCTs; or a body of evidence consisting principally of studies rated as 1+ directly applicable to the target population and demonstrating overall consistency of results

B A body of evidence including studies rated as 2++ directly applicable to the target population and demonstrating overall consistency of results; or extrapolated evidence from studies rated as $1++$ or $1+$

C A body of evidence including studies rated as 2+ directly applicable to the target population and demonstrating overall consistency of results; or extrapolated evidence from studies rated as $2++$

D Evidence level 3 or 4; or extrapolated evidence from studies rated as $2+$.

For interventions analyzed in a single study, no recommendation was made.

\section{Summary of statements and recommendations}

$\nabla$

- Pancreatitis is the most frequent complication after ERCP with an incidence of 3.5\% in unselected patients; it is of mild or moderate severity in approximately $90 \%$ of cases. Independent patient-related and procedure-related risk factors for PEP are listed in Table 1. Risk factors synergistically increase the risk of PEP (Evidence level 1+).

- There is no evidence that hospital ERCP volume has an influence on the incidence of PEP; data about a potential relationship between PEP incidence and endoscopist case volume are conflicting. Low annual case volumes, of endoscopists and centers, are associated with higher ERCP failure rates (Evidence level 2+).

- Serum amylase values less than 1.5 times the upper limit of normal (ULN), obtained at 2 - 4 hours post-ERCP, almost exclude PEP; values more than 3 or 5 times the ULN at 4-6 hours post-ERCP have increasing positive predictive values for PEP (Evidence level 2+). It is recommended that serum amylase be determined in patients to be discharged on the day of ERCP; patients with amylase values less than 1.5 times ULN can be discharged without concern about risk of PEP (Recommendation grade B).

- Nonsteroidal anti-inflammatory drugs (NSAIDs) reduce the incidence of PEP; effective PEP prophylaxis has only been demonstrated using $100 \mathrm{mg}$ of diclofenac or indomethacin administered rectally (Evidence level 1++). Routine rectal administration of $100 \mathrm{mg}$ of diclofenac or indomethacin, immediately before or after ERCP, is recommended (Recommendation grade A).

- Nitroglycerin reduces the incidence of PEP; however, when administered transdermally, it is ineffective (Evidence level 1++). Side effects such as transient hypotension and headache may occur. We do not recommend the routine use of nitroglycerin for prophylaxis of PEP (Recommendation grade $\mathrm{A}$ ).

- Cephtazidime reduced the incidence of PEP in a single study (Evidence level 1-). Further data are needed before recommending cephtazidime for the prophylaxis of PEP (Recommendation grade $\mathrm{C}$ ).

- Based on an ad hoc meta-analysis of results from 10 high quality RCTs, somatostatin proved to be ineffective in preventing PEP (Evidence level 1++). We do not recommend universal administration of prophylactic somatostatin in average-risk patients undergoing ERCP (Recommendation grade A). Administration of somatostatin might be more efficacious using specific dose schedules, but caution is needed when interpreting the results of subgroup analyses as they often exaggerate differences between treatments in RCTs.

- Octreotide administration did not affect the overall incidence of PEP when data from eight high quality trials were pooled (Evidence level 1++). Prophylaxis with octreotide is not recommended (Recommendation grade A). In future studies the efficacy of prophylactic administration of octreotide should be evaluated using a dose greater than or equal to $0.5 \mathrm{mg}$.

- Prophylaxis with gabexate or ulinastatin does not reduce the incidence of PEP (Evidence level 1++). Neither drug is recommended for prophylaxis of PEP (Recommendation grade A).

- There is no evidence that glucocorticoids, drugs reducing sphincter of Oddi pressure (other than nitroglycerin), antioxidants, heparin, interleukin-10, or some anti-inflammatory drugs (other than diclofenac and indomethacin), such as pentoxifylline, semapimod and the recombinant platelet-activating factor acetylhydrolase reduce the incidence of PEP (Evidence levels from 1- to 1++). None of these drugs is recommended for PEP prophylaxis (Recommendation grade $\mathrm{A}$ ).

- There is no evidence that the incidence of PEP is influenced by patient position during ERCP (Evidence level 2++). Therefore, no recommendation is made regarding patient position.

- Trauma resulting from repeated attempts at biliary cannulation has been proven to be a risk factor for the development of PEP (Evidence level 2++). The number of cannulation attempts should be minimized (Recommendation grade $\mathrm{B}$ ).

- Injection of contrast medium into the pancreatic duct is an independent predictor of PEP (Evidence level 1+). If pancreatic duct injection occurs incidentally or is required, the number of injections and volume of contrast medium injected into the pancreatic duct should be kept as low as possible (Recommendation grade B).

- Compared with traditional, high-osmolality contrast agents, low-osmolality contrast agents are costlier but are not associated with reduction in the rates of PEP (Evidence level 1-). The routine use of these agents for ERCP is not recommended (Recommendation grade $\mathrm{B}$ ). 


\begin{tabular}{|c|c|c|}
\hline & $\begin{array}{l}\text { Adjusted odds ratios }(95 \% \mathrm{Cl} \\
\text { in parentheses except where } \\
\text { indicated otherwise) }\end{array}$ & $\begin{array}{l}\text { Pooled incidence of PEP } \\
\text { in patients with vs. those } \\
\text { without risk factor }\end{array}$ \\
\hline \multicolumn{3}{|l|}{ Patient-related risk factors } \\
\hline \multicolumn{3}{|l|}{ Definite risk factors } \\
\hline Suspected SOD & $4.09(3.37-4.96)$ & $10.3 \%$ vs. $3.9 \%$ \\
\hline Female gender & $2.23(1.75-2.84)$ & $4.0 \%$ vs. $2.1 \%$ \\
\hline Previous pancreatitis & $2.46(1.93-3.12)$ & $6.7 \%$ vs. $3.8 \%$ \\
\hline \multicolumn{3}{|l|}{ Likely risk factors } \\
\hline Younger age & $1.09-2.87$ (range $1.09-6.68$ ) & $6.1 \%$ vs. $2.4 \%$ \\
\hline Non-dilated extrahepatic bile ducts & NR & $6.5 \%$ vs. $6.7 \%$ \\
\hline Absence of chronic pancreatitis & $1.87(1.00-3.48)$ & $4.0 \%$ vs. $3.1 \%$ \\
\hline Normal serum bilirubin & $1.89(1.22-2.93)$ & $10.0 \%$ vs. $4.2 \%$ \\
\hline \multicolumn{3}{|l|}{ Procedure-related risk factors } \\
\hline \multicolumn{3}{|l|}{ Definite risk factors } \\
\hline Precut sphincterotomy & $2.71(2.02-3.63)$ & $5.3 \%$ vs. $3.1 \%$ \\
\hline Pancreatic injection & $2.2(1.60-3.01)$ & $3.3 \%$ vs. $1.7 \%$ \\
\hline \multicolumn{3}{|l|}{ Likely risk factors } \\
\hline High number of cannulation attempts $\dagger$ & $2.40-3.41$ (range $1.07-5.67$ ) & $3.7 \%$ vs. $2.3 \%$ \\
\hline Pancreatic sphincterotomy & $3.07(1.64-5.75)$ & $2.6 \%$ vs. $2.3 \%$ \\
\hline Biliary balloon sphincter dilation & $4.51(1.51-13.46)$ & $9.3 \%$ vs. $1.9 \%$ \\
\hline Failure to clear bile duct stones & $3.35(1.33-9.10)$ & $1.7 \%$ vs. $1.6 \%$ \\
\hline \multicolumn{3}{|c|}{$\begin{array}{l}\text { ERCP, endoscopic retrograde cholangiopancreatography; CI, confidence interval; SOD, sphincter of Oddi dysfunction; NR, not } \\
\text { reported. } \\
\text { * For definite risk factors, adjusted odds ratios and pooled incidences of PEP are reproduced from Masci et al. [10]. For likely } \\
\text { risk factors, adjusted odds ratios are reproduced from included studies that identified the characteristic as an independent risk } \\
\text { factor, while pooled incidences were calculated using figures available in all of the included studies that provided sufficient } \\
\text { data for calculation (see text for details about included studies) }[2,11-14] \text {. } \\
\dagger \text { "High" (vs. low) number of cannulation attempts was defined as number of attempts before final cannulation of the desired }\end{array}$} \\
\hline
\end{tabular}

Table 1 Independent risk factors for post-ERCP pancreatitis (PEP).*
- Use of carbon dioxide (CO2) as a replacement for air for luminal insufflation during ERCP does not influence the incidence of PEP but decreases the incidence and severity of post-procedural $a b$ dominal pain (Evidence level 1+). Carbon dioxide is recommended for insufflation, and might be particularly useful for outpatient ERCPs, to reduce post-procedural abdominal pain and to avoid confusion with PEP (Recommendation grade B).

- For deep biliary cannulation, the wire-guided technique reduces the risk of PEP and increases the success rate of primary cannulation when compared with the standard contrast-assisted method (Evidence level 1++). The wire-guided technique is recommended for deep biliary cannulation (Recommendation grade $\mathrm{A}$ ).

- The incidence of post-sphincterotomy pancreatitis is not influenced by the type of electrosurgical current used (whether purecut or blended) (Evidence level 1+). Blended current is recommended for biliary sphincterotomy, particularly in patients at high risk of bleeding (Recommendation grade A).

- Data about the usefulness and safety of pancreatic guide wire placement to facilitate biliary cannulation in difficult cases are conflicting. Prophylactic pancreatic stent placement decreases the incidence of PEP with this technique (Evidence level 2+). Pancreatic guide wire assistance may facilitate biliary cannulation mostly in the case of inadvertent but repeated cannulation of the pancreatic duct; if this method is used, a pancreatic stent should be placed for PEP prophylaxis (Recommendation grade B).

- Various techniques of precut biliary sphincterotomy have been described; the fistulotomy technique may present a lower incidence of PEP than standard needle-knife sphincterotomy, but further RCTs are required to determine which technique is safer and more effective, based upon the papillary anatomy. There is no evidence that the success and complication rates of biliary precut are affected by the level of endoscopist experience in this technique but published data only report on the experience of one endoscopist (Evidence level 2-). Prolonged cannulation attempts using standard techniques may impart a risk for PEP greater than the precut sphincterotomy itself (Evidence level 2 +). Precut sphincterotomy should be performed by endoscopists with expertise in standard cannulation techniques (Recommendation grade $\mathrm{D}$ ). The decision to perform precut biliary sphincterotomy, the timing, and the technique are based on anatomic findings, endoscopist preference and procedural indication (Recommendation grade C).

- Compared with endoscopic sphincterotomy, endoscopic papillary balloon dilation (EPBD) using small-caliber balloons ( $\leq 10$ $\mathrm{mm}$ ) is associated with a significantly higher incidence of PEP and significantly less bleeding (Evidence level 1++). EPBD is not recommended as an alternative to sphincterotomy in routine ERCP but may be useful in patients with coagulopathy and altered anatomy (e.g. Billroth II) (Recommendation grade A). If balloon dilation is performed in young patients, the placement of a prophylactic pancreatic stent should be strongly considered (Evidence level 4; Recommendation grade D).

- Potential advantages of performing large-balloon dilation in addition to endoscopic sphincterotomy for extraction of difficult biliary stones remain unclear (Evidence level 3). Endoscopic sphincterotomy plus large-balloon dilation does not seem to increase the risk of PEP and can avoid the need for mechanical lithotripsy in selected patients, but not enough data are available to recommend routine use over biliary sphincterotomy alone in conjunction to lithotripsy techniques(RecommendationgradeD).

- In patients undergoing pancreatic sphincter of Oddi manometry, use of the standard perfusion catheter, without an aspira- 
tion port, has been shown to increase the risk of PEP compared with modified water perfusion catheters (Evidence level 2++). Pancreatic sphincter of Oddi manometry should be done using a modified triple-lumen perfusion catheter with simultaneous aspiration or a microtransducer catheter (non-water-perfused) (Recommendation grade B).

- Prophylactic pancreatic stent placement is recommended to prevent PEP in patients who are at high risk for development of PEP. Short 5-Fr diameter plastic pancreatic stents are currently recommended. Passage of the stent from the pancreatic duct should be evaluated within 5 to 10 days of placement and retained stents should be promptly removed endoscopically (Evidence level 1+; Recommendation grade A).

\section{Definitions}

$\nabla$

The consensus definition of ERCP complications as proposed by Cotton et al. has allowed standardized reporting of the incidence and severity of PEP [2]. PEP was originally defined as "clinical pancreatitis with amylase at least three times normal at more than 24 hours after the procedure, requiring hospital admission or a prolongation of planned admission." Some variations exist across studies in the interpretation of "clinical pancreatitis," and this has been defined by some as "new or worsened abdominal pain" [2], "typical pain and symptoms" [3], or "abdominal pain and tenderness" [4]. The definition used by Freeman et al. (new or worsened abdominal pain) takes into account patients who undergo ERCP in the setting of acute pancreatitis or a flare of chronic pancreatitis [2]. The current grading system for the severity of PEP is mainly based on the length of hospitalization: mild PEP is defined as need for hospital admission or prolongation of planned admission up to 3 days; moderate PEP is defined by need for hospitalization of 4-10 days, and severe PEP by hospitalization for more than 10 days, or hemorrhagic pancreatitis, phlegmon (now referred to as pancreatic necrosis), or pseudocyst, or need for percutaneous drainage or surgical intervention [5]. Although the current classification system allows the severity of pancreatitis to be determined in retrospective studies, we recommend that more specific grading systems of pancreatitis severity (e.g. the Atlanta Classification System) be used in future prospective studies [6].

In the absence of chronic pancreatitis, an elevated serum amylase is frequently seen 24 hours after ERCP (53\% in a prospective study). Abdominal pain in the absence of PEP occurred in $62 \%$ of cases in an RCT when air, rather than carbon dioxide, was used for luminal insufflation during ERCP $[7,8]$. Therefore, a standard threshold level for serum amylase (three times the upper limit of normal [ULN] values 24 hours post-ERCP) and clinical examination of patients by an evaluator blinded to the allocated treatment group are important in RCTs that assess the effectiveness of interventions to prevent PEP.

\section{Incidence, risk factors, and severity of PEP \\ $\nabla$}

- Pancreatitis is the most frequent complication after ERCP with an incidence of $3.5 \%$ in unselected patients; it is of mild or moderate severity in approximately $90 \%$ of cases. Independent patient-related and procedure-related risk factors for PEP are listed in Table 1. Risk factors synergistically increase the risk of PEP (Evidence level 1+).
Based on a systematic review of 21 prospective studies involving more than 16000 patients [9], PEP was found to be the most frequent complication following ERCP with an incidence of $3.47 \%$ (95\% confidence interval [CI], 3.19\%-3.75\%). As defined previously, PEP can be mild, moderate, or severe. Based upon data from studies that have included unselected patients, PEP is mild in $45 \%$, moderate in $44 \%$, and severe in $11 \%$ of cases, and causes death in $3 \%$ of cases (95\%CI, $1.65 \%-4.51 \%)$. Stratification of patients into low-risk or high-risk categories for PEP is important in order to provide adequate pre-procedure information to the patient and in deciding when to consider patient referral to a tertiary center.

Based on a large meta-analysis [10], three patient-related and two procedure-related characteristics are considered definite independent risk factors for PEP ( $\bullet$ Table 1 ). Known or suspected sphincter of Oddi dysfunction (SOD) presents the strongest association, with an incidence of PEP close to $10 \%$. As only five potential risk factors for PEP were analyzed in that meta-analysis, we also reviewed prospective, multicenter studies that analyzed potential risk factors for PEP using multivariate analysis. Five studies were selected that involved 13745 patients in total $[2,11$ 14]. Patient-related and procedure-related characteristics independently associated with PEP in at least one of these studies are reported as likely risk factors in $\bullet$ Table 1 ("pancreatic injection" corresponded to $\geq 1$ injection and, depending on studies, a "high number of cannulation attempts" to more than five or more than one attempts before cannulation of the desired ducts). The risk factors presented in Table 1 are not exhaustive because not all potential risk factors have been analyzed. For example, ampullectomy is generally considered to be a definitive risk factor for PEP on the basis of several small prospective studies $[15,16]$.

As risk factors for PEP were shown to be independent by multivariate analysis, they might have a cumulative effect. Freeman et al. calculated the adjusted odds ratio (OR) for various combinations of risk factors by using data prospectively collected from about 2000 ERCPs: the highest risk of PEP (42\%) was found for female patients with a normal serum bilirubin, suspected SOD, and difficult biliary cannulation [11]. The actual incidence and severity of PEP in high-risk conditions is estimated using data from control arms of RCTs in which the effectiveness of prophylactic pancreatic stent placement was evaluated (patients were selected for inclusion based on the presence of SOD, a common bile duct diameter $<10 \mathrm{~mm}$, precutting, difficult cannulation, sphincter of Oddi manometry, ampullectomy, and also simple endoscopic sphincterotomy) [15,17-19]. Meta-analysis of the control arms of four such trials found a PEP incidence of $24.1 \%$; $84.4 \%$ of cases were mild/moderate and $15.6 \%$ were severe [20].

- There is no evidence that hospital ERCP volume has an influence on the incidence of PEP; data about a potential relationship between PEP incidence and endoscopist case volume are conflicting. Low annual case volumes, of endoscopists and centers, are associated with higher ERCP failure rates (Evidence level 2+).

Factors that may affect the outcome of ERCP that are specifically related to hospital procedure volume include availability of equipment and adequacy of anesthesia, endoscopic and radiologic support, and nursing assistance. The number of ERCPs performed in many centers is not as high as commonly believed: in three large (regional or national) studies, the median annual number of ERCPs was between 49 and 235 [21 -23]. In one large study, the median annual number of ERCPs per endoscopist was 
111 and $40 \%$ of endoscopists performed fewer than 50 sphincterotomies/year [24].

Case mix is likely to be different in low-volume vs. high-volume centers and might impact the reported PEP incidence rates: for instance, the prevalence of suspected SOD was $11.7 \%$ in studies included in a meta-analysis by Masci et al. [10], but was only $1.5 \%$ in a large audit representative of ERCP practice in England, and $2.2 \%$ in a study from eight US community hospitals $[14,25]$. Thus centers with a specific interest in reporting data about risk factors for PEP appear to have a higher percentage of patients with suspected SOD reflecting a referral bias for high-risk patients in these centers.

Multivariate analyses from two prospective audits performed in England and Italy (66 and 9 centers, respectively) found there was no significant association between annual hospital volume of ERCPs and incidence of PEP [12,14]. Nevertheless, the Italian study found that overall complications and cholangitis were more frequent in low-volume vs. high-volume centers [12]. A large US study (> 2500 hospitals) analyzed the relationship between hospital procedure volume and ERCP outcome [22]. Complication rates could not be assessed due to limitations of the database used. Higher hospital ERCP volume was associated with a lower incidence of failed procedures though not with in-hospital mortality or PEP.

Endoscopist ERCP volume may refer to either lifetime volume or annual number of ERCPs performed; annual volume has been the parameter most thoroughly studied. In two prospective multicenter studies by Freeman et al. [2,11], no relationship between incidence of PEP and endoscopist case volume was seen using multivariate analysis. PEP was significantly more frequent in the hands of endoscopists with high case volume, but the association became nonsignificant after adjusting for other risk factors at multivariate analysis [11]. The success rate for bile duct cannulation was higher for endoscopists performing an average of more than two ERCPs/week [11]. In another prospective study [26], the most significant risk factor for PEP following endoscopic sphincterotomy was performance by endoscopists who performed a low number (fewer than 40 ) of sphincterotomies per year. However, this was a single-center study that did not evaluate known risk factors for PEP.

\section{Prediction of PEP}

- Serum amylase values less than 1.5 times the upper limit of normal (ULN), obtained at $2-4$ hours post-ERCP, almost exclude PEP; values more than 3 or 5 times the ULN at 4-6 hours post$E R C P$ have increasing positive predictive values for PEP (Evidence level 2+). It is recommended that serum amylase be determined in patients to be discharged on the day of ERCP; patients with amylase values less than 1.5 times ULN can be discharged without concern about risk of PEP (Recommendation grade $\mathrm{B}$ ).

In a study that involved 231 patients, the 2-hour serum amylase level was more accurate than clinical assessment in distinguishing PEP from other causes of abdominal pain: serum amylase levels less than $276 \mathrm{IU} / \mathrm{L}$ or more than 6 times the ULN at 2 hours post-ERCP ruled out or predicted PEP, respectively, in almost $100 \%$ of cases [27]. In another prospective study that involved 1185 ERCPs, serum amylase values obtained 6 hours post-ERCP that were less than 3.0 times the ULN were never associated with PEP and values more than 5.0 times the ULN were associated with PEP in $90 \%$ of cases [28]. A similar predictive value for PEP of serum amylase increase to more than 5.0 times ULN 6 hours post-
ERCP was reported recently by Kapetanos et al. [29]. A study from Australia emphasized the value of a normal or only slightly elevated serum amylase at 4 hours post-ERCP for ruling out PEP: amylase values less than 1.5 times ULN had a negative predictive value of $100 \%$ and could be used as a reliable criterion to discharge patients; serum amylase values more than 3.0 times ULN had a positive predictive value of $36.8 \%$ and were used as a cutoff value for hospital admission [30]. If the amylase value is between 1.5 and 3.0 times ULN, then clinical assessment and risk factors for PEP should guide management. More recently, Ito et al. found that if the serum amylase was normal at 3 hours after ERCP only $1 \%$ of patients developed PEP compared with $39 \%$ if the amylase was more than 5.0 times ULN [31].

\section{Pharmacologic agents available for PEP prophylaxis} $\nabla$

Most available data on the efficacy of pharmacological agents for PEP prophylaxis have been obtained in patients at average risk for PEP. In such circumstances, insufficient statistical power might account for the absence of demonstrated drug efficacy: in an RCT that would include low-risk patients undergoing low-risk ERCP, it is estimated that recruitment of a total of 2300 patients would be needed (with a randomization ratio $1: 1$ ) to provide sufficient statistical power to detect a risk reduction from $4 \%$ to $2 \%$. Conversely, if high-risk patients were included in an RCT, it is estimated that recruitment of a total of 400 patients would be needed (with a randomization ratio $1: 1$ ) to provide sufficient statistical power to detect a risk reduction from $20 \%$ to $10 \%$. There are no published trials with sufficient sample sizes based upon these rates of PEP.

\section{Drugs with proven efficacy}

Nonsteroidal anti-inflammatory drugs (NSAIDs)

- NSAIDs reduce the incidence of PEP; effective PEP prophylaxis has only been demonstrated using $100 \mathrm{mg}$ of diclofenac or indomethacin administered rectally (Evidence level 1++). Routine rectal administration of $100 \mathrm{mg}$ of diclofenac or indomethacin immediately before or after ERCP is recommended (Recommendation grade $\mathrm{A}$ ).

Three different meta-analyses have been published using data obtained from four prospective, randomized, placebo-controlled studies which compared rectally administered diclofenac or indomethacin at a dose of $100 \mathrm{mg}$ vs. placebo [32 - 34]. No statistical heterogeneity was detected across the studies. Two RCTs evaluated the effect of rectal administration of $100 \mathrm{mg}$ diclofenac immediately after the procedure, while the other two evaluated rectal administration of $100 \mathrm{mg}$ indomethacin immediately before the procedure. Both studies showed similar results. Patients who were considered to be at high risk for PEP were included in two studies. Overall, PEP occurred in 20/456 (4.4\%) patients in the treatment groups vs. $57 / 456$ (12.5\%) patients in the placebo groups with an estimated pooled relative risk (RR) of 0.36 (95\% $\mathrm{CI}, 0.22-0.60$ ), and the number needed to treat (NNT) to prevent one episode of PEP was 15. The administration of NSAIDs was associated with a similar decrease in the incidence of PEP regardless of risk [34]. No adverse events attributable to NSAIDs were reported. 
Possibly effective drugs

Glyceryl trinitrate (nitroglycerin)

- Nitroglycerin reduces the incidence of PEP; however, when administered transdermally, it is ineffective (Evidence grade 1++). Side effects such as transient hypotension and headache may occur. We do not recommend the routine use of nitroglycerin for prophylaxis of PEP (Recommendation grade A).

The influence of nitroglycerin on the incidence of PEP was evaluated in two meta-analyses that pooled data from five RCTs involving 1662 patients $[35,36]$. The studies were homogeneous and both meta-analyses showed an overall significant reduction of PEP with a RR of $0.61(95 \% \mathrm{CI}, 0.44-0.86)$ and NNT of 26 . In the majority of patients nitroglycerin was administered transdermally. When a subanalysis was restricted to these patients, transdermal nitroglycerin failed to show a significant reduction in PEP (RR 0.66; 95\%CI, 0.43-1.01) The use of nitroglycerin was associated with a significant risk of transient hypotension and headache.

\section{Ceftazidime}

- Ceftazidime reduced the incidence of PEP in a single study (Evidence grade 1-). Further data are needed before recommending ceftazidime for the prophylaxis of PEP (Recommendation grade C).

In the only study using ceftazidime for prophylaxis of PEP, the administration of this antibiotic ( $2 \mathrm{~g}$ intravenously 30 minutes prior to ERCP) resulted in a significant reduction in the incidence of PEP compared with controls (15/160 [9.4\%] vs. 4/155 [2.6\%], $P=0.009$ ) [37]. This study was of low methodological quality owing to unclear allocation concealment (the control group received "no antibiotics" in place of placebo).

\section{Somatostatin}

- Based on an ad hoc meta-analysis of results from ten highquality RCTs, somatostatin proved to be ineffective in preventing PEP (Evidence level 1++). We do not recommend universal administration of prophylactic somatostatin in average-risk patients undergoing ERCP (Recommendation grade A). Administration of somatostatin might be more efficacious using specific dose schedules, but caution is needed when interpreting the results of subgroup analyses as they often exaggerate differences between treatments in RCTs.

The prophylactic use of somatostatin for prevention of PEP has been studied. In an ad hoc meta-analysis of 10 high-quality (Jadad score $>3$ ) trials $[4,38-46]$, the incidence of PEP was $5.1 \%$ (79/1542) in the somatostatin group compared with 7.6\% (115/ 1507 ) in the placebo group. No single trial had a sufficient sample size, and data were highly heterogeneous across the studies $\left(I^{2}\right.$, 67.97; $P<0.001)$. Overall, the use of somatostatin did not result in a reduction of PEP with an odds ratio (OR) of 0.57 (95\%CI, $0.32-1.03$ ). An interesting observation was that when the baseline incidence of PEP among controls was higher than $10 \%$ a benefit of somatostatin was seen, but when the baseline incidence was approximately $5 \%$ no benefit was seen. When trials with an incidence of PEP greater than $10 \%$ in the placebo group were excluded from analysis [38 - 40], the incidence of PEP in the placebo group dropped to $6.7 \%(88 / 1322)$, whereas it was $4.9 \%$ (57/1364) in the somatostatin group.

Administration of somatostatin as a single bolus injection was evaluated in two small-sized studies; data proved statistically homogeneous and pooling their effects yielded a significant protection of PEP, with a 9.9\% PEP incidence in controls (20/202) vs.
$2.0 \%$ in drug-treated patients $(4 / 198)$ (OR, $0.19 ; 95 \% \mathrm{CI}, 0.06-$ $0.63)[40,42]$. The NNT was 13 . The infusion of somatostatin for longer than 12 hours for PEP prophylaxis was explored in four RCTs: the pooled estimate showed that there was a significant reduction in PEP incidence from $7.4 \%$ in controls (48/648) to $3.2 \%$ (20/632) in the active drug group; the OR was significant at 0.42 $(95 \% \mathrm{CI}, 0.22-0.83)$ although data were heterogeneous $\left(I^{2}, 55.98\right.$; $P<0.01$ ). The NNT was 24 . With a shorter duration of infusion (less than 6 hours), somatostatin prophylaxis was ineffective.

\section{Octreotide}

- Octreotide administration did not affect the overall incidence of PEP when data from eight high-quality trials were pooled (Evidence level 1++). Prophylaxis with octreotide is not recommended (Recommendation grade A). In future studies the efficacy of prophylactic administration of octreotide should be evaluated using a dose greater than or equal to $0.5 \mathrm{mg}$.

An ad hoc meta-analysis was performed by pooling the data from eight high-quality RCTs (Jadad score $\geq 3$ ). The incidence of PEP was $8.3 \%(78 / 945)$ in the placebo group vs. $6.0 \%(56 / 933)$ in the active drug group [ $47-54]$. Data from original studies were heterogeneous $\left(I^{2}, 52.39 ; P=0.04\right)$ and the corresponding $\mathrm{OR}(0.73$; $95 \% \mathrm{CI}, 0.41-1.30$ ) was nonsignificant. A subanalysis of administration of octreotide either before ERCP or before and after ERCP showed that neither schedule was effective. The effect of the drug seemed to be dose-related as octreotide was ineffective at a dosage of less than $0.5 \mathrm{mg}$, but beneficial at higher doses: PEP incidence was $3.7 \%(26 / 706)$ in patients who received more than $0.5 \mathrm{mg}$ of octreotide, and $7.5 \%$ (53/710) in control patients. Data were homogeneous across the trials, and the corresponding OR was significant $(0.48 ; 95 \% \mathrm{CI}, 0.29-0.79)$ with an NNT of 26.

\section{Antiprotease drugs}

- Prophylaxis with gabexate or ulinastatin does not reduce the incidence of PEP (Evidence 1++). Neither drug is recommended for prophylaxis of PEP (Recommendation grade A).

The benefit of gabexate for prevention of PEP has been evaluated in six high-quality RCTs [38,39, 41,55-57]. The incidence of PEP was $6.3 \%(83 / 1318)$ in controls vs. $4.5 \%(68 / 1509)$ in patients receiving the active drug. Data across individual trials were highly heterogeneous $\left(I^{2}, 64.09 ; P=0.016\right)$ and the pooled effect did not show a significant difference (OR, $0.65 ; 95 \% \mathrm{CI}, 0.36-1.185)$. The schedule of gabexate administration did not influence the outcome as neither a short duration of drug infusion (less than 6 hours) nor a long one (more than 12 hours) were beneficial.

Ulinastatin as an agent to prevent PEP was studied in four RCTs. In two studies it was compared with placebo and in two it was compared with gabexate. The results of these studies are contradictory [58-61]. In one RCT that included 406 patients [59], the incidence of PEP was significantly lower with ulinastatin (150 $000 \mathrm{U}$ administered prior to ERCP) compared with placebo (2.9\% vs. $7.4 \%, P=0.041$ ). However, this benefit was not confirmed in another RCT in which 227 patients were randomly allocated to receive either ulinastatin (100 $000 \mathrm{U}$ ) or placebo immediately after ERCP (PEP incidence $6.7 \%$ and $5.6 \%$, respectively; $P>0.05$ ) [61]. Two Japanese clinical trials compared gabexate with ulinastatin administered before and after ERCP, and the rates of PEP were not significantly different ( $4.3 \%$ vs. $7.5 \%$ in one trial and $2.9 \%$ vs. $2.9 \%$ in the other) $[58,60]$. 


\section{Drugs proven ineffective ( $\bullet$ Table 2 )}

- There is no evidence that glucocorticoids, drugs reducing sphincter of Oddi pressure (other than nitroglycerin), antioxidants, heparin, interleukin-10, or some anti-inflammatory drugs (other than diclofenac and indomethacin) such as pentoxifylline, semapimod, and the recombinant platelet-activating factor acetylhydrolase, reduce the incidence of PEP (Evidence levels from 1- to 1++). None of these drugs is recommended for $P E P$ prophylaxis (Recommendation grade $\mathrm{A}$ ).

\section{Glucocorticoids}

The efficacy of glucocorticoids for PEP prophylaxis has been evaluated in two meta-analyses including six RCTs $[62,63]$. The incidence of PEP was not significantly different and was $11.8 \%$ (144/ $1221)$ in the corticosteroid group vs. $10.6 \%(130 / 1227)$ in the control group.

\section{Drugs reducing sphincter of Oddi pressure \\ (other than nitroglycerin)}

Botulinum toxin [64], epinephrine [65], lidocaine [66], and nifedipine $[67,68]$, were tested as prophylactic agents for PEP, based on the their potential effect of reducing sphincter of Oddi pressure. The corresponding RCTs failed to show efficacy of these drugs [64-68].

\section{Antioxidant drugs}

Three antioxidant agents have been tested for PEP prophylaxis in seven RCTs, including allopurinol, N-acetylcysteine, and natural beta-carotene. Three meta-analyses of four RCTs that involved 1730 patients proved that allopurinol was ineffective for PEP prophylaxis (RR, 0.86; 95\%CI, $0.42-1.77$ ) [69-71]. The benefit of $\mathrm{N}$ acetylcysteine for preventing PEP has been evaluated in two RCTs: the pooled incidence of PEP was similar in the active drug and control groups ( $10.6 \%$ vs. $10.2 \%$, respectively) [ 72,73$]$. The effect of natural beta-carotene in the prevention of PEP was evaluated in a single study that enrolled a total of 321 patients: betacarotene was not found to be effective for prevention of PEP [74].
Heparin

The potential of subcutaneous heparin as a prophylactic agent for PEP has been evaluated in two RCTs that included 564 patients $[75,76]$. Both studies lacked sufficient statistical power due to inadequate sample size. Single-study and pooled data disproved the benefit of this drug. Of note, heparin at selected timings and doses in these studies did not appear to increase the risk of postsphincterotomy bleeding compared with placebo.

\section{Interleukin-10}

In three RCTs involving a total of 649 patients, the efficacy of recombinant human interleukin-10 as an agent for PEP prophylaxis was studied [77-79]. In the initial study [77], a single intravenous injection of interleukin-10 at two different doses (4 or $20 \mu \mathrm{g} / \mathrm{kg}$ ) administered 30 minutes prior to therapeutic ERCP significantly decreased the incidence and severity of PEP (from $24.4 \%$ in the placebo arm to $10.4 \%$ and $6.8 \%$ in patients receiving either low-dose or high-dose interleukin-10). In this study, the incidence of PEP in the placebo group was higher than expected for patients at average risk. Two subsequent trials did not confirm a benefit $[78,80]$.

\section{Other pharmacologic agents}

Three different anti-inflammatory drugs (pentoxifylline, semapimod and recombinant platelet-activating factor acetylhydrolase) tested in RCTs have not been found to reduce PEP [81 - 83].

\section{ERCP technique}

\section{$\nabla$}

\section{General considerations}

- There is no evidence that the incidence of PEP is influenced by patient position during ERCP (Evidence level 2++). Therefore, no recommendation is made regarding patient position.

Two RCTs, involving 154 patients in total, compared the supine and prone positions during ERCP $[84,85]$. Overall, the incidence of PEP was $2.6 \%$, without significant difference between groups.

- Trauma resulting from repeated attempts at biliary cannulation has been proven to be a risk factor for the development of PEP

Table 2 Summary of studies for drugs not found to be effective for PEP prophylaxis.

\begin{tabular}{|c|c|c|c|c|c|}
\hline & \multicolumn{2}{|c|}{ Studies, n } & \multirow{2}{*}{$\begin{array}{l}\text { Category of risk for PEP } \\
\text { (number of patients) }\end{array}$} & \multicolumn{2}{|c|}{ Pooled incidence of PEP, \% } \\
\hline & RCTs & Patients, $\mathbf{n}$ & & Active drug & Control arm \\
\hline Glucocorticoids $[62,63]$ & 6 & 2448 & Average & 11.8 & 10.6 \\
\hline $\begin{array}{l}\text { Drugs reducing sphincter of } \\
\text { Oddi pressure [64-68] }\end{array}$ & 5 & 1011 & $\begin{array}{l}\text { Average }(n=985) \\
\text { High risk }(n=26)[64]\end{array}$ & $\begin{array}{l}4.1 \\
25\end{array}$ & $\begin{array}{l}5.2 \\
43\end{array}$ \\
\hline Antioxidants [69-74] & 7 & 2413 & $\begin{array}{l}\text { Average }(n=555) \\
\text { Low risk }(n=1300) \\
\text { High risk }(n=558)\end{array}$ & $\begin{array}{l}9 \\
7.2 \\
26.5\end{array}$ & $\begin{array}{l}9.7 \\
7.7 \\
21.2\end{array}$ \\
\hline Heparin $[75,76]$ & 2 & 564 & $\begin{array}{l}\text { Average [75] } \\
\text { High risk }(n=458)[76]\end{array}$ & $\begin{array}{l}7.8 \\
8.1\end{array}$ & $\begin{array}{l}7.4 \\
8.8\end{array}$ \\
\hline Interleukin-10 [77-79] & 3 & 649 & $\begin{array}{l}\text { Average }(n=344) \\
\text { High risk }(n=305)[79]\end{array}$ & $\begin{array}{l}10.7^{*} \\
15.4 \dagger\end{array}$ & $\begin{array}{l}13.9 \\
14.3\end{array}$ \\
\hline Others $\ddagger$ [81-83] & 3 & 1162 & $\begin{array}{l}\text { Average }(n=562) \\
\text { High risk }(n=600)[82]\end{array}$ & $\begin{array}{l}7.2 \\
15.9 \S\end{array}$ & $\begin{array}{l}8.1 \\
19.6\end{array}$ \\
\hline
\end{tabular}

PEP, post-ERCP pancreatitis; RCT, randomized controlled trial

* Interleukin-10 administered at a dosage of $4-8 \mu \mathrm{g} / \mathrm{kg}$

$\dagger$ Interleukin-10 administered at a dosage of $20 \mu \mathrm{g} / \mathrm{kg}$

$\ddagger$ Pentoxifylline, semapimod, and recombinant platelet-activating factor acetylhydrolase

$\S$ Recombinant platelet-activating factor acetylhydrolase: $5 \mathrm{mg} / \mathrm{kg}$ 
(Evidence level 2++). The number of cannulation attempts should be minimized (Recommendation grade $B$ ).

The risk of PEP is higher after multiple attempts at duct cannulation $[2,14,86]$.

- Injection of contrast medium into the pancreatic duct is an independent predictor of PEP (Evidence level 1+). If pancreatic duct injection occurs incidentally or is required, the number of injections and volume of contrast medium injected into the pancreatic duct should be kept as low as possible (Recommendation grade B).

In a large meta-analysis, pancreatic duct injection was found to be an independent predictor of PEP (RR, 2.2; 95\%CI, 1.60-3.01; $P<0.001$ ) [10]. In a retrospective study that included more than 14000 ERCP procedures the extent of pancreatic duct injection (head only vs. head and body vs. injection to the tail) was independently associated with PEP [87], but this was not an independent risk factor in a prospective investigation [86].

- Compared with traditional, high-osmolality contrast agents, low-osmolality contrast agents are costlier but are not associated with reduction in the rates of PEP (Evidence level 1-). The routine use of these agents for ERCP is not recommended (Recommendation grade B).

A meta-analysis of 13 RCTs that involved 3381 patients found no significant difference in PEP rates between high-osmolality and low-osmolality contrast agents [88]. The meta-analysis had some limitations, including inconsistencies between definitions of PEP among studies and lack of risk stratification.

- Use of carbon dioxide (CO2) as a replacement for air for luminal insufflation during ERCP does not influence the incidence of PEP but decreases the incidence and severity of post-procedural abdominal pain (Evidence level 1+). Carbon dioxide is recommended for insufflation, and might be particularly useful for outpatient ERCPs, to reduce post-procedural abdominal pain and to avoid confusion with PEP (Recommendation grade B).

Clearance of gases from the bowel following endoscopy is faster when carbon dioxide replaces nitrogen and oxygen, the two main components of air, by estimated factors of 160 and 12 , respectively. This is mainly due to the higher solubility of carbon dioxide in water compared with other gases. Three RCTs, involving 282 patients in total, have been published in which insufflation of air was compared with carbon dioxide for luminal distension during ERCP $[8,89,90]$. The incidence and severity of postprocedural pain was significantly lower with carbon dioxide up to 2 hours after ERCP. This may help avoid the clinical interpretation of post-procedural abdominal pain as being PEP.

- For deep biliary cannulation, the wire-guided technique reduces the risk of PEP and increases the success rate of primary cannulation when compared with the standard contrast-assisted method (Evidence level 1++). The wire-guided technique is recommended for deep biliary cannulation (Recommendation grade $\mathrm{A}$ ).

The wire-guided biliary cannulation technique entails passage of a 0.035-inch diameter guide wire inserted through a catheter (most often a hydrophilic guide wire inserted into a sphincterotome). Cannulation can be achieved either by pushing the wire directly into the papilla or by inserting the sphincterotome into the papilla and then advancing the guide wire. Four meta-analyses have analyzed the RCTs in which the safety and efficacy of wire-guided vs. standard contrast-assisted cannulation of the common bile duct were compared and showed similar results [91 -94]. Two of these meta-analyses are fully published; they included 1762 patients from five of the RCTs [91], and 2128 pa- tients from seven of the RCTs [94]. As two RCTs presented a crossover design that did not allow cases of PEP to be ascribed to a single technique, the analyses were restricted to non-crossover RCTs (thus three and five in number, respectively) [91,94]. The ORs for prevention of PEP were lower in the wire-guided cannulation group compared with the standard contrast-assisted cannulation group for both meta-analyses $(0.23$ [95\%CI, $0.13-0.41]$ and 0.38 [95\%CI, 0.19-0.76], respectively) [91,94]. Both meta-analyses showed that the wire-guided cannulation technique had the additional advantage of providing a significantly higher rate of primary cannulation.

- The incidence of post-sphincterotomy pancreatitis is not influenced by the type of electrosurgical current used (whether purecut or blended) (Evidence level 1+). Blended current is recommended for biliary sphincterotomy, particularly in patients at high risk of bleeding (Recommendation grade A).

As pure-cut current produces less edema than blended current [95], it was hypothesized that its use might reduce the incidence of PEP after biliary sphincterotomy. A meta-analysis of four RCTs that included 804 patients found no significant difference in the incidence of PEP between pure and blended current [90]. However, the incidence of bleeding was significantly higher when pure-cut current was used.

\section{Effect of difficult biliary cannulation}

The definition of difficult biliary cannulation varies and includes failure of deep cannulation of the desired duct after 10-15 attempts or after 10 minutes, as well as 5 unintentional cannulations of the undesired duct. In such events, commonly used options include persistent attempts at cannulation using standard accessories, the use of the guide wire-assisted cannulation technique, performance of precut sphincterotomy, and patient referral.

\section{Pancreatic guide wire-assisted technique}

- Data about the usefulness and safety of pancreatic guide wire placement to facilitate biliary cannulation in difficult cases are conflicting. Prophylactic pancreatic stent placement decreases the incidence of PEP with this technique (Evidence level 2+). Pancreatic guide wire assistance may facilitate biliary cannulation mostly in the case of inadvertent but repeated cannulation of the pancreatic duct; if this method is used, a pancreatic stent should be placed for prophylaxis (Recommendation grade B). In the pancreatic guide wire-assisted technique, a guide wire is inserted in the main pancreatic duct to facilitate biliary cannulation by straightening the papillary anatomy and to prevent repeated cannulation of the pancreatic duct. This technique has been used in selected cases (i.e., patients with unintentional pancreatic cannulation in whom pancreatic guide wire placement is relatively easy) [96]. Two RCTs have compared this technique with persistence in standard cannulation, with divergent results $[96,97]$. In the first RCT no cases of PEP occurred in either group. In the more recent RCT, the incidence of PEP was higher with the pancreatic guide wire-assisted technique (17\%) than with the standard cannulation technique $(8 \%)$ but the difference was not statistically significant.

Ito et al. randomly allocated 69 patients to receive either a $5-\mathrm{Fr}$ pancreatic stent or no pancreatic stent after pancreatic guide wire placement for biliary cannulation: the incidence of PEP was lower in the stent group vs. the no-stent group (2.9\% vs. $23 \%$, respectively; RR, 0.13; $95 \% C I, 0.02-0.97$ ) [98]. Since prophylactic pancreatic stent placement may be particularly easy when the pancreatic guide wire-assisted technique is used (because the 
guide wire is already in place), stent placement is strongly recommended [99]. In six series comprising more than 20 patients with difficult biliary cannulation per study (totaling 408 patients), the pancreatic guide wire-assisted technique allowed successful biliary cannulation in $73 \%$ of cases [96,97,100-103]. Some authors suggest that in cases of failed biliary cannulation with the pancreatic guide wire-assisted technique, a plastic pancreatic stent should be inserted followed by precut sphincterotomy [102].

\section{Precut biliary sphincterotomy}

- Various techniques of precut biliary sphincterotomy have been described; the fistulotomy technique may present a lower incidence of PEP than standard needle-knife sphincterotomy but further RCTs are required to determine which technique is safer and more effective, based upon the papillary anatomy. There is no evidence that the success and complication rates of biliary precut are affected by the level of endoscopist experience in this technique but published data only report on the experience of one endoscopist (Evidence level 2-). Prolonged cannulation attempts using standard techniques may impart a risk for PEP greater than the precut sphincterotomy itself (Evidence level $2+)$. Precut sphincterotomy should be performed by endoscopists with expertise in standard cannulation techniques (Recommendation grade $\mathrm{D}$ ). The decision to perform precut biliary sphincterotomy, the timing, and the technique, are based on anatomic findings, endoscopist preference, and procedural indication (Recommendation grade $\mathrm{C}$ ).

Compared with biliary cannulation using standard techniques, the use of precut sphincterotomy increases the success rate of selective biliary cannulation but also the incidence of PEP $[2,10,13,104,105]$. However, it remains unclear whether the added risk of the precut technique is related to the precut itself or to the prolonged effort at cannulation that often precedes it. The incidence of complications following precut was reported by three endoscopists at different stages of their experience: in all studies, the incidence of PEP remained stable with increasing endoscopic experience [106-108]. The overall incidence of complications was higher at the beginning of the experience in one of these studies, but most complications consisted of minor bleeding requiring neither blood transfusion nor need for repeat endoscopy [106]. Final success rate of biliary cannulation was also similar at various experience levels [106-108].

Four RCTs have tested the hypothesis that the high incidence of PEP reported with precut was related to the prolonged period of cannulation attempts that precede precut rather than to the technique itself [104,109-111]. Patients were randomly allocated to early precut or otherwise to precut only after prolonged cannulation attempts using standard techniques as the initial technique for biliary cannulation (one RCT) or to precut only after failed attempts using standard techniques for 5-12 minutes (three RCTs). Aside from the definition of early precut, differences between studies included the technique of precut and the randomization ratio (from $1: 1$ to $1: 3$ ). All procedures were performed by endoscopists experienced in precut techniques. The overall incidence of PEP was lower in patients randomly allocated to early precut than to persistence using standard techniques $(2.8 \%$ [8/ $290]$. vs. $6.4 \%$ [23/360]; $P=0.04)$.
Specific therapeutic techniques

Balloon dilation of the biliary sphincter

(balloon sphincteroplasty)

- Compared with endoscopic sphincterotomy, endoscopic papillary balloon dilation (EPBD) using small-caliber balloons $(\leq 10 \mathrm{~mm})$ is associated with a significantly higher incidence of PEP and significantly less bleeding (Evidence level 1++). EPBD is not recommended as an alternative to sphincterotomy in routine ERCP but may be useful in patients with coagulopathy and altered anatomy (e.g. Billroth II) (Recommendation grade A). If balloon dilation is performed in young patients, the placement of a prophylactic pancreatic stent should be strongly considered (Evidence level 4, Recommendation grade D).

The use of EPBD may be advantageous compared with endoscopic sphincterotomy by decreasing clinically significant bleeding in patients with coagulopathy, for preserving sphincter of Oddi function in younger patients [112], and in removing bile duct stones in patients with altered anatomy (Billroth II) where sphincterotomy is technically difficult. In two meta-analyses, the use of EPBD resulted in a lower success rate than endoscopic sphincterotomy for the initial removal of biliary stones, with a significantly higher incidence of PEP and significantly lower incidence of bleeding $[113,114]$. Concerns were raised about the risk of severe life-threatening PEP in young patients after EPBD, based upon the results of a multicenter US RCT in which significantly higher rates of severe morbidity $(P=0.004)$, including severe PEP $(P=0.01)$, were seen following sphincteroplasty compared with endoscopic sphincterotomy [115]. However, this study was performed before the use of pancreatic stents for PEP prophylaxis. Therefore, placement of a prophylactic pancreatic stent should be strongly considered in patients undergoing EPBD, especially younger patients.

- Potential advantages of performing large-balloon dilation in addition to endoscopic sphincterotomy for extraction of difficult biliary stones remain unclear (Evidence level 3). Endoscopic sphincterotomy plus large-balloon dilation does not seem to increase the risk of PEP and can avoid the need for mechanical lithotripsy in selected patients, but not enough data are available to recommend routine use over biliary sphincterotomy alone in conjunction with lithotripsy techniques (Recommendation grade D).

Several case series have reported results of using a modified technique to remove large or difficult common bile duct stones that consists of endoscopic sphincterotomy followed by dilation using a large-diameter (12-20 mm) balloon [116-120]. Most of these case series included patients in whom extraction of biliary stones using standard basket/balloon techniques had failed. Following sphincterotomy and large-balloon dilation, the success rates for stone extraction without the need for mechanical lithotripsy were high. The incidence of PEP did not seem excessive compared with that reported in patients undergoing endoscopic sphincterotomy alone, perhaps because the force of the balloon is exerted in the direction of the biliary sphincterotomy and away from the pancreatic duct orifice. However, the only RCT reported to date that compared endoscopic sphincterotomy alone vs. endoscopic sphincterotomy combined with large balloon dilation found no differences in rates of successful stone clearance, need for mechanical lithotripsy, and complication [121]. Large-balloon dilation in combination with endoscopic sphincterotomy may be useful in patients with a tapered distal bile duct or in altered anatomy (e.g. Billroth II) that limits the extent of biliary sphincterotomy. 


\section{Sphincter of Oddi manometry}

- In patients undergoing pancreatic sphincter of Oddi manometry, use of the standard perfusion catheter without an aspiration port has been shown to increase the risk of PEP compared with modified water perfusion catheters (Evidence level 2++). Pancreatic sphincter of Oddi manometry should be done using a modified triple-lumen perfusion catheter with simultaneous aspiration or a microtransducer catheter (non-water-perfused) (Recommendation grade B).

To reduce the risk of possible perfusion-related hydrostatic pancreatic injury, modified perfusion catheters have been developed. These include a modified triple-lumen catheter that allows aspiration of the perfused fluid from the pancreas, a sleeve assembly in which the fluid is reverse-perfused so that perfusate enters the duodenum rather than the pancreatic duct, and a microtransducer catheter that uses solid-state technology [122 - 125]. Excellent correlation of manometry results has been demonstrated between the standard perfusion catheter and the microtransducer catheter as well as the sleeve assembly device $[122,126]$. Three RCTs comparing incidence of PEP after using the standard perfusion catheter vs. other catheters have been performed; two of these have found a significantly lower incidence of PEP with the alternative catheter compared with the standard perfusion catheter (3.0\% vs. $23.5 \%, P=0.01 ; 3.1 \%$ vs. $13.8 \%, P<0.05)$, and in the third RCT no episodes of PEP occurred $[125,127,128]$.

\section{Role of pancreatic stent placement for PEP prophylaxis \\ $\nabla$}

- Prophylactic pancreatic stent placement is recommended to prevent PEP in patients who are at high risk for development of PEP. Short, 5-Fr diameter, plastic pancreatic stents are currently recommended. Passage of the stent from the pancreatic duct should be evaluated within 5 to 10 days of placement and retained stents should be promptly removed endoscopically (Evidence level 1+; Recommendation grade A).

Two independent meta-analyses on the use of pancreatic stent placement for PEP prophylaxis in patients at high risk for PEP have demonstrated that stent placement significantly reduced the incidence of PEP $[20,129]$. The most recent meta-analysis was the most robust because, in addition to the analysis of six prospective controlled studies, it provided separate analysis of the four available RCTs and used intention-to-treat principles (by assuming that patients in whom attempted prophylactic pancreatic stent placement failed actually developed PEP if the clinical outcome was not stated in the original study) [20,129]. Using this approach, the OR for PEP was 0.44 in the stent group vs. the no-stent group $(95 \% \mathrm{CI}, 0.24-0.81 ; P=0.009)$, with an absolute risk reduction of $12.0 \%(95 \% \mathrm{CI}, 3.0-21.0)$. A large multicenter RCT (201 patients) was subsequently published and showed a decreased incidence of PEP when prophylactic pancreatic stent placement was performed, regardless of the presence or absence of risk factors for PEP (PEP incidence in the stent and no-stent groups was $3.2 \%$ vs. $13.6 \%$, respectively; $P=0.019$ ) [130]. What is also clear from these studies is that the risk of severe pancreatitis is nearly eliminated following successful placement of a prophylactic pancreatic stent.

Different types of plastic stents have been used. Although nasopancreatic catheters were used in early studies, more recent studies have mostly used 3-Fr and 5-Fr diameter pancreatic stents. In two recent RCTs that compared 5-Fr with 3-Fr stents,
5-Fr stents proved equivalent to 3-Fr stents in most outcomes, but successful insertion of 5-Fr stents was achieved significantly more often $[131,132]$. Straight polyethylene stents measuring 5 $\mathrm{Fr}$ in diameter and 2 or $3 \mathrm{~cm}$ in length without internal flanges and with one or two external flanges (on the duodenal side) are often used. Using this type of stent, spontaneous elimination at 2 weeks post-ERCP occurred in more than $95 \%$ of 200 patients $[130,131]$. In the absence of spontaneous migration out of the pancreatic duct at 5-10 days post-ERCP (as determined by plain abdominal X-ray), prompt endoscopic stent removal is recommended because of the increased risk of PEP (RR, 5.2 in patients without vs. with spontaneous stent elimination at 2 weeks) and potential for stent-induced damage to the pancreatic duct $[131,133]$.

Prophylactic pancreatic stent placement is cost-effective in patients at high risk for PEP, but not in those at average risk [134]. Caution should be used when attempting prophylactic pancreatic stent placement because the incidence of PEP after failed attempts may be as high as 65\% [135]. Therefore prophylactic pancreatic stent placement in high-risk patients is cost-effective only if the success rate of pancreatic stent placement is more than $75 \%$.

Surveys of physician practices have shown that expert pancreaticobiliary endoscopists from the US and Canada commonly place prophylactic pancreatic stents, but most European endoscopists do not $[136,137]$. Findings from the currently most recent survey showed that: (i) endoscopists who did not place prophylactic pancreatic stents cited lack of experience in this technique as the reason; and (ii) measurement of PEP incidence and an annual hospital volume of more than 500 ERCPs were independently associated with the use of prophylactic pancreatic stent placement [137].

\section{Selection of measures for PEP prophylaxis \\ $\checkmark$}

- For low-risk ERCPs, periprocedural rectal administration of nonsteroidal anti-inflammatory drugs (NSAIDs) is recommended. For high-risk ERCPs, prophylactic pancreatic stent placement should be strongly considered (Evidence level 1+; Recommendation grade $\mathrm{A}$ ).

In the setting of ERCP the following conditions are considered to represent high risk for PEP: endoscopic ampullectomy (papillectomy), known or suspected SOD, pancreatic sphincterotomy, precut biliary sphincterotomy, pancreatic guide wire-assisted biliary cannulation, endoscopic balloon sphincteroplasty, and presence of more than two of the risk factors listed in $\square$ Table 1. Procedures and patient conditions that do not fulfill these criteria are considered to represent low risk for PEP.

\section{Competing interests: None.}

\section{Institutions}

1 Service of Gastroenterology and Hepatology, Geneva University Hospitals, Geneva, Switzerland

2 Division of Gastroenterology, Casa Sollievo Sofferemza Hospital, IRCCS, San Giovanni Rotondo, Italy

3 Departments of Gastroenterology and Hepato-Pancreatology, Erasme University Hospital, Brussels, Belgium

${ }^{4}$ Division of Gastroenterology and Gastrointestinal Endoscopy, Vita-Salute San Raffaele University, IRCCS San Raffaele Hospital, Milan, Italy

5 Department of Medicine, Division of Gastroenterology and Hepatology, Mayo Medical Center, Rochester, Minnesota, USA 


\section{References}

1 Harbour R, Miller J. A new system for grading recommendations in evidence based guidelines. BMJ 2001; 323: 334 - 336

2 Freeman ML, Nelson DB, Sherman $S$ et al. Complications of endoscopic biliary sphincterotomy. N Engl J Med 1996; 335: 909-918

3 Choi CW, Kang DH, Kim GH et al. Nafamostat mesylate in the prevention of post-ERCP pancreatitis and risk factors for post-ERCP pancreatitis. Gastrointest Endosc 2009; 69: e11 - e18

4 Lee KT, Lee DH, Yoo BM. The prophylactic effect of somatostatin on post-therapeutic endoscopic retrograde cholangiopancreatography pancreatitis. Pancreas 2008; 37: 445-448

5 Cotton PB, Lehman G, Vennes J et al. Endoscopic sphincterotomy complications and their management: an attempt at consensus. Gastrointest Endosc 1991; 37: 383 - 393

6 Bradley EL. A clinically based classification system for acute pancreatitis. Summary of the International Symposium on Acute Pancreatitis, Atlanta, GA, September 11 through 13, 1992: Arch Surg 1993; 128 $586-590$

7 Testoni PA, Caporuscio S, Bagnolo F, Lella F. Twenty-four-hour serum amylase predicting pancreatic reaction after endoscopic sphincterotomy. Endoscopy 1999; 31: 131 - 136

8 Bretthauer M, Seip B, Aasen S et al. Carbon dioxide insufflation for more comfortable endoscopic retrograde cholangiopancreatography: a randomized, controlled, double-blind trial. Endoscopy 2007; 39: 58 - 64

9 Andriulli A, Loperfido S, Napolitano G et al. Incidence rates of post-ERCP complications: a systematic survey of prospective studies. Am J Gastroenterol 2007; 102: 1781 - 1788

10 Masci E, Mariani A, Curioni S, Testoni PA. Risk factors for pancreatitis following endoscopic retrograde cholangiopancreatography: a metaanalysis. Endoscopy 2003; 35: $830-834$

11 Freeman ML, DiSario JA, Nelson DB et al. Risk factors for post-ERCP pancreatitis: a prospective, multicenter study. Gastrointest Endosc 2001; 54: $425-434$

12 Loperfido S, Angelini G, Benedetti $G$ et al. Major early complications from diagnostic and therapeutic ERCP: a prospective multicenter study. Gastrointest Endosc 1998; 48: 1-10

13 Masci E, Toti G, Mariani A et al. Complications of diagnostic and therapeutic ERCP: a prospective multicenter study. Am J Gastroenterol 2001; 96: 417-423

14 Williams EJ, Taylor S, Fairclough P et al. Risk factors for complication following ERCP; results of a large-scale, prospective multicenter study. Endoscopy 2007; 39: 793-801

15 Harewood GC, Pochron NL, Gostout CJ. Prospective, randomized, controlled trial of prophylactic pancreatic stent placement for endoscopic snare excision of the duodenal ampulla. Gastrointest Endosc 2005; 62: $367-370$

16 Norton ID, Gostout CJ, Baron TH et al. Safety and outcome of endoscopic snare excision of the major duodenal papilla. Gastrointest Endosc 2002; 56: 239-243

17 Fazel A, Quadri A, Catalano MF, Meyerson SM, Geenen JE. Does a pancreatic duct stent prevent post-ERCP pancreatitis? A prospective randomized study. Gastrointest Endosc 2003; 57: 291 - 294

18 Smithline A, Silverman W, Rogers D et al. Effect of prophylactic main pancreatic duct stenting on the incidence of biliary endoscopic sphincterotomy-induced pancreatitis in high-risk patients. Gastrointest Endosc 1993; 39: $652-657$

19 Tarnasky PR, Palesch YY, Cunningham JT et al. Pancreatic stenting prevents pancreatitis after biliary sphincterotomy in patients with sphincter of Oddi dysfunction. Gastroenterology 1998; 115: 1518 - 1524

20 Andriulli A, Forlano R, Napolitano $G$ et al. Pancreatic duct stents in the prophylaxis of pancreatic damage after endoscopic retrograde cholangiopancreatography: a systematic analysis of benefits and associated risks. Digestion 2007; 75: 156- 163

21 Williams EJ, Taylor S, Fairclough P et al. Are we meeting the standards set for endoscopy? Results of a large-scale prospective survey of endoscopic retrograde cholangio-pancreatograph practice. Gut 2007; 56 $821-829$

22 Varadarajulu S, Kilgore ML, Wilcox CM, Eloubeidi MA. Relationship among hospital ERCP volume, length of stay, and technical outcomes. Gastrointest Endosc 2006; 64: 338-347

23 Allison MC, Ramanaden DN, Fouweather MG, Davis DK, Colin-Jones DG. Provision of ERCP services and training in the United Kingdom. Endoscopy 2000; 32: 693-699
24 Hilsden RJ, Romagnuolo J, May GR. Patterns of use of endoscopic retrograde cholangiopancreatography in a Canadian province. Can J Gastroenterol 2004; 18: 619-624

25 Colton J, Curran C. Quality indicators, including complications, of ERCP in a community setting: a prospective study. Gastrointest Endosc 2009; 70: $457-467$

26 Rabenstein T, Roggenbuck S, Framke B et al. Complications of endoscopic sphincterotomy: can heparin prevent acute pancreatitis after ERCP? Gastrointest Endosc 2002; 55: 476- 483

27 Gottlieb K, Sherman S, Pezzi J, Esber E, Lehman GA. Early recognition of post-ERCP pancreatitis by clinical assessment and serum pancreatic enzymes. Am J Gastroenterol 1996; 91: 1553-1557

28 Testoni PA, Bagnolo F. Pain at 24 hours associated with amylase levels greater than 5 times the upper normal limit as the most reliable indicator of post-ERCP pancreatitis. Gastrointest Endosc 2001; 53: 33 - 39

29 Kapetanos D, Kokozidis G, Kinigopoulou P et al. The value of serum amylase and elastase measurements in the prediction of post-ERCP acute pancreatitis. Hepato-Gastroenterol 2007; 54: 556-560

30 Thomas PR, Sengupta S. Prediction of pancreatitis following endoscopic retrograde cholangiopancreatography by the 4 -h post procedure amylase level. J Gastroenterol Hepatol 2001; 16: 923-926

31 Ito $K$, Fujita N, Noda Y et al. Relationship between post-ERCP pancreatitis and the change of serum amylase level after the procedure. World J Gastroenterol 2007; 13: 3855-3860

32 Dai H-F, Wang X-W, Zhao K. Role of nonsteroidal anti-inflammatory drugs in the prevention of post-ERCP pancreatitis: a meta-analysis Hepatobiliary Pancreat Dis Int 2009; 8: 11-16

33 Elmunzer B, Waljee A, Elta $G$ et al. A meta-analysis of rectal NSAIDs in the prevention of post-ERCP pancreatitis. Gut 2008; 57: 1262

34 Zheng $M-H$, Xia $H$, Chen Y-P. Rectal administration of NSAIDs in the prevention of post-ERCP pancreatitis: a complementary meta-analysis. Gut 2008; 57: 1632

35 Bang UC, Nojgaard C, Andersen PK, Matzen P. Meta-analysis: Nitroglycerin for prevention of post-ERCP pancreatitis. Aliment Pharmacol Ther 2009; 29: 1078 - 1085

36 Shao LM, Chen QY, Chen MY, Cai JT. Nitroglycerin in the prevention of post-ERCP pancreatitis: a meta-analysis. Dig Dis Sci 2010; 55: 1-7

37 Raty S, Sand J, Pulkkinen M, Matikainen M, Nordback I. Post-ERCP pancreatitis: reduction by routine antibiotics. J Gastrointest Surg 2001; 5 : 339-345; discussion 345

38 Andriulli A, Clemente R, Solmi L et al. Gabexate or somatostatin administration before ERCP in patients at high risk for post-ERCP pancreatitis: a multicenter, placebo-controlled, randomized clinical trial. Gastrointest Endosc 2002; 56: 488 - 495

39 Andriulli A, Solmi L, Loperfido S et al. Prophylaxis of ERCP-related pancreatitis: a randomized, controlled trial of somatostatin and gabexate mesylate. Clin Gastroenterol Hepatol 2004; 2: 713 - 718

40 Arvanitidis D, Anagnostopoulos GK, Giannopoulos D et al. Can somatostatin prevent post-ERCP pancreatitis? Results of a randomized controlled trial. J Gastroenterol Hepatol 2004; 19: 278 - 282

41 Benvenutti S, Zancanella L, Piazzi L et al. Prevention of post-ERCP pancreatitis with somatostatin versus gabexate mesylate: A randomized placebo controlled multicenter study. Dig Liv Dis 2006; 38: S15

42 Bordas JM, Toledo-Pimentel V, Llach J et al. Effects of bolus somatostatin in preventing pancreatitis after endoscopic pancreatography: results of a randomized study. Gastrointest Endosc 1998; 47: 230-234

43 Persson B, Slezak P, Efendic S, Haggmark A. Can somatostatin prevent injection pancreatitis after ERCP? Hepatogastroenterology 1992; 39: 259-261

44 Poon RT, Yeung C, Liu CL et al. Intravenous bolus somatostatin after diagnostic cholangiopancreatography reduces the incidence of pancreatitis associated with therapeutic endoscopic retrograde cholangiopancreatography procedures: a randomised controlled trial. Gut 2003; 52: $1768-1773$

45 Poon RT, Yeung C, Lo CM et al. Prophylactic effect of somatostatin on post-ERCP pancreatitis: a randomized controlled trial. Gastrointest Endosc 1999; 49: 593-598

46 Saari A, Kivilaakso E, Schroder T. The influence of somatostatin on pancreatic irritation after pancreatography. An experimental and clinical study. Surg Res Comm 1988; 2: 271 - 278

47 Arcidiacono R, Gambitta P, Rossi A et al. The use of a long-acting somatostatin analogue (octreotide) for prophylaxis of acute pancreatitis after endoscopic sphincterotomy. Endoscopy 1994; 26: 715-718

48 Duvnjak M, Supanc V, Simicevic VN et al. Use of octreotide-acetate in preventing pancreatitis-like changes following therapeutic endoscopic 
retrograde cholangiopancreatography. Acta Med Croatica 1999; 53 : $115-118$

49 Hardt PD, Kress O, Fadgyas T et al. Octreotide in the prevention of pancreatic damage induced by endoscopic sphincterotomy. Eur J Med Res 2000; 5: 165 - 170

50 Li ZS, Pan X, Zhang WJ et al. Effect of octreotide administration in the prophylaxis of post-ERCP pancreatitis and hyperamylasemia: A multicenter, placebo-controlled, randomized clinical trial. Am J Gastroenterol 2007; 102: 46- 51

51 Manolakopoulos S, Avgerinos A, Vlachogiannakos J et al. Octreotide versus hydrocortisone versus placebo in the prevention of post-ERCP pancreatitis: a multicenter randomized controlled trial. Gastrointest Endosc 2002; 55: 470-475

52 Sternlieb JM, Aronchick CA, Retig JN et al. A multicenter, randomized, controlled trial to evaluate the effect of prophylactic octreotide on ERCP-induced pancreatitis. Am J Gastroenterol 1992; 87: 1561 - 1566

53 Testoni PA, Bagnolo F, Andriulli A et al. Octreotide 24-h prophylaxis in patients at high risk for post-ERCP pancreatitis: results of a multicenter, randomized, controlled trial. Aliment Pharmacol Ther 2001; 15: $965-972$

54 Thomopoulos KC, Pagoni NA, Vagenas KA et al. Twenty-four hour prophylaxis with increased dosage of octreotide reduces the incidence of post-ERCP pancreatitis. Gastrointest Endosc 2006; 64: 726 - 731

55 Cavallini G, Tittobello A, Frulloni L et al. Gabexate for the prevention of pancreatic damage related to endoscopic retrograde cholangiopancreatography. Gabexate in digestive endoscopy - Italian Group. N Engl J Med 1996; 335: 919-923

56 Manes G, Ardizzone S, Lombardi G et al. Efficacy of postprocedure administration of gabexate mesylate in the prevention of post-ERCP pancreatitis: a randomized, controlled, multicenter study. Gastrointest Endosc 2007; 65: 982 - 987

57 Xiong GS, Wu SM, Zhang XW, Ge ZZ. Clinical trial of gabexate in the prophylaxis of post-endoscopic retrograde cholangiopancreatography pancreatitis. Braz J Med Biol Res 2006; 39: 85-90

58 Fujishiro $H$, Adachi $\mathrm{K}$, Imaoka $\mathrm{T}$ et al. Ulinastatin shows preventive effect on post-endoscopic retrograde cholangiopancreatography pancreatitis in a multicenter prospective randomized study. J Gastroenterol Hepatol 2006; 21: 1065-1069

59 Tsujino T, Komatsu $Y$, Isayama $\mathrm{H}$ et al. Ulinastatin for pancreatitis after endoscopic retrograde cholangiopancreatography: a randomized, controlled trial. Clin Gastroenterol Hepatol 2005; 3: 376 - 383

60 Ueki T, Otani K, Kawamoto Ket al. Comparison between ulinastatin and gabexate mesylate for the prevention of post-endoscopic retrograde cholangiopancreatography pancreatitis: a prospective, randomized trial. J Gastroenterol 2007; 42: 161 - 167

61 Yoo JW, Ryu JK, Lee SH et al. Preventive effects of ulinastatin on post-endoscopic retrograde cholangiopancreatography pancreatitis in highrisk patients: a prospective, randomized, placebo-controlled trial. Pancreas 2008; 37: $366-370$

62 Bai Y, Gao J, Shi X, Zou D, Li Z. Prophylactic corticosteroids do not prevent post-ERCP pancreatitis: a meta-analysis of randomized controlled trials. Pancreatology 2008; 8: 504- 509

63 Zheng M, Bai J, Yuan B et al. Meta-analysis of prophylactic corticosteroid use in post-ERCP pancreatitis. BMC Gastroenterol 2008; 8: 6

64 Gorelick A, Barnett J, Chey W, Anderson M, Elta G. Botulinum toxin injection after biliary sphincterotomy. Endoscopy 2004; 36: 170 - 173

65 Matsushita M, Takakuwa H, Shimeno $N$ et al. Epinephrine sprayed on the papilla for prevention of post-ERCP pancreatitis. J Gastroenterol 2009; 44: $71-75$

66 Schwartz JJ, Lew RJ, Ahmad NA et al. The effect of lidocaine sprayed on the major duodenal papilla on the frequency of post-ERCP pancreatitis. Gastrointest Endosc 2004; 59: 179-184

67 Prat F, Amaris J, Ducot B et al. Nifedipine for prevention of post-ERCP pancreatitis: a prospective, double-blind randomized study. Gastrointest Endosc 2002; 56: 202-208

68 Sand J, Nordback I. Prospective randomized trial of the effect of nifedipine on pancreatic irritation after endoscopic retrograde cholangiopancreatography. Digestion 1993; 54: 105-111

69 Bai Y, Gao J, Zhang W, Zou D, Li Z. Meta-analysis: allopurinol in the prevention of postendoscopic retrograde cholangiopancreatography pancreatitis. Aliment Pharmacol Ther 2008; 28: 557-564

70 Zheng $M$, Chen Y, Bai J et al. Meta-analysis of prophylactic allopurinol use in post-endoscopic retrograde cholangiopancreatography pancreatitis. Pancreas 2008; 37: 247-253
71 Andriulli A, Annese V. Risk of post-endoscopic retrograde cholangiopancreatography pancreatitis and ways to prevent it: old myths, a current need? The case of allopurinol. Clin Gastroenterol Hepatol 2008; 6: $374-376$

72 Katsinelos P, Kountouras J, Paroutoglou G et al. Intravenous N-acetylcysteine does not prevent post-ERCP pancreatitis. Gastrointest Endosc 2005; 62: 105 - 111

73 Milewski J, Rydzewska G, Degowska M, Kierzkiewicz M, Rydzewski A. Nacetylcysteine does not prevent post-endoscopic retrograde cholangiopancreatography hyperamylasemia and acute pancreatitis. World J Gastroenterol 2006; 12: 3751 - 3755

74 Lavy A, Karban A, Suissa A et al. Natural beta-carotene for the prevention of post-ERCP pancreatitis. Pancreas 2004; 29: e45 - e50

75 Barkay O, Niv E, Santo E et al. Low-dose heparin for the prevention of post-ERCP pancreatitis: a randomized placebo-controlled trial. Surg Endosc 2008; 22: 1971 - 1976

76 Rabenstein T, Fischer B, Wiessner Vet al. Low-molecular-weight heparin does not prevent acute post-ERCP pancreatitis. Gastrointest Endosc 2004; 59: $606-613$

77 Deviere J, Le Moine O, Van Laethem JL et al. Interleukin 10 reduces the incidence of pancreatitis after therapeutic endoscopic retrograde cholangiopancreatography. Gastroenterology 2001; 120: 498 - 505

78 Dumot JA, Conwell DL, Zuccaro G Jr et al. A randomized, double blind study of interleukin 10 for the prevention of ERCP-induced pancreatitis. Am J Gastroenterol 2001; 96: 2098 - 2102

79 Sherman S, Cheng CL, Costamagna G et al. Efficacy of recombinant human interleukin-10 in prevention of post-endoscopic retrograde cholangiopancreatography pancreatitis in subjects with increased risk. Pancreas 2009; 38: 267 - 274

80 Sherman S, Cheng C-L, Costamagna $G$ et al. Efficacy of recombinant human interleukin-10 in prevention of post-endoscopic retrograde cholangiopancreatography pancreatitis in subjects with increased risk. Pancreas 2009; 38: $267-274$

81 Kapetanos D, Kokozidis G, Christodoulou D et al. A randomized controlled trial of pentoxifylline for the prevention of post-ERCP pancreatitis. Gastrointest Endosc 2007; 66: 513-518

82 Sherman S, Alazmi WM, Lehman GA et al. Evaluation of recombinant platelet-activating factor acetylhydrolase for reducing the incidence and severity of post-ERCP acute pancreatitis. Gastrointest Endosc 2009; 69: 462 - 472

83 van Westerloo DJ, Rauws EA, Hommes D et al. Pre-ERCP infusion of semapimod, a mitogen-activated protein kinases inhibitor, lowers postERCP hyperamylasemia but not pancreatitis incidence. Gastrointest Endosc 2008; 68: 246-254

84 Terruzzi V, Radaelli F, Meucci G, Minoli G. Is the supine position as safe and effective as the prone position for endoscopic retrograde cholangiopancreatography? A prospective randomized study. Endoscopy 2005; $37: 1211-1214$

85 Tringali A, Mutignani M, Milano A, Perri V, Costamagna G. No difference between supine and prone position for ERCP in conscious sedated patients: a prospective randomized study. Endoscopy 2008; 40: 93 - 97

86 Vandervoort J, Soetikno RM, Tham TCK et al. Risk factors for complications after performance of ERCP. Gastrointest Endosc 2002; 56: 652 656

87 Cheon YK, Cho KB, Watkins JL et al. Frequency and severity of post-ERCP pancreatitis correlated with extent of pancreatic ductal opacification. Gastrointest Endosc 2007; 65: 385 - 393

88 George S, Kulkarni AA, Stevens G, Forsmark CE, Draganov P. Role of osmolality of contrast media in the development of post-ERCP pancreatitis: a meta-analysis. Dig Dis Sci 2004; 49: 503 - 508

89 Keswani $R$, Hovis $R$, Edmunowicz $S$ et al. Carbon dioxide $\left(\mathrm{CO}_{2}\right)$ insufflation during ERCP for the reduction of post-procedure pain: preliminary results of a randomized, double-blind controlled trial. Gastrointest Endosc 2008; 67: AB107

90 Maple JT, Keswani RN, Hovis RM et al. Carbon dioxide insufflation during ERCP for reduction of postprocedure pain: a randomized, doubleblind, controlled trial. Gastrointest Endosc 2009; 70: 278-283

91 Cennamo V, Fuccio L, Zagari RM et al. Can a wire-guided cannulation technique increase bile duct cannulation rate and prevent post-ERCP pancreatitis?: A meta-analysis of randomized controlled trials. Am J Gastroenterol 2009; 104: 2343-2350

92 Choudhary A, Puli S, Ibdah J, Bechtold M. Guidewire use for prevention of post ERCP pancreatitis: a meta-analysis of randomized controlled trials. Gastrointest Endosc 2009; 69: AB305 
93 Madhoun M, Te C, Stoner J, Maple J. Does wire-guided cannulation prevent post-ERCP pancreatitis? A meta-analysis. Gastrointest Endosc 2009; 69: AB132

94 Cheung J, Tsoi KK, Quan W-L, Lau JYW, Sung JJY. Guidewire versus conventional contrast cannulation of the common bile duct for the prevention of post-ERCP pancreatitis: a systematic review and meta-analysis. Gastrointest Endosc 2009; 70: 1211 - 1219

95 Verma D, Kapadia A, Adler DG. Pure versus mixed electrosurgical current for endoscopic biliary sphincterotomy: a meta-analysis of adverse outcomes. Gastrointest Endosc 2007; 66: 283 - 290

96 Herreros de Tejada A, Calleja JL, Díaz G et al. Double-guidewire technique for difficult bile duct cannulation: a multicenter randomized, controlled trial. Gastrointest Endosc 2009; 70: 700 - 709

97 Maeda S, Hayashi H, Hosokawa $O$ et al. Prospective randomized pilot trial of selective biliary cannulation using pancreatic guide-wire placement. Endoscopy 2003; 35: $721-724$

98 Ito K, Fujita N, Noda Y et al. Can pancreatic duct stenting prevent postERCP pancreatitis in patients who undergo pancreatic guidewire placement for achieving selective biliary cannulation? A prospective randomized controlled trial. Endoscopy 2008; 40 (Suppl 1): A17

99 Nguyen-Tang T, Dumonceau JM. Double-guidewire technique for difficult bile duct cannulation: why not insert a prophylactic pancreatic stent? Gastrointest Endosc 2010; in press:

100 Iqbal S, Sharma $P$, Shah S. Role of double guide wire cannulation during ERCP. Gastrointest Endosc 2008; 67: AB158

101 Ito K, Fujita N, Noda $Y$ et al. Pancreatic guidewire placement for achieving selective biliary cannulation during endoscopic retrograde cholangio-pancreatography. World J Gastroenterol 2008; 14: 5595 5600; discussion 5599

102 Patel S, Torres V, Gross G. The early use of the double-wire technique to facilitate difficult biliary cannulation and its impact on post-ERCP pancreatitis. Gastrointest Endosc 2009; 69: AB159

103 Gyökeres T, Duhl J, Varsányi M et al. Double guide wire placement for endoscopic pancreaticobiliary procedures. Endoscopy 2003; 35: 95 96

104 Cennamo V, Fuccio L, Repici A et al. Timing of precut procedure does not influence success rate and complications of ERCP procedure: a prospective randomized comparative study. Gastrointest Endosc 2009; 69: $473-479$

105 Wang P, Li Z-S, Liu F et al. Risk factors for ERCP-related complications: a prospective multicenter study. Am J Gastroenterol 2009; 104: 31 40

106 Akaraviputh T, Lohsiriwat V, Swangsri J et al. The learning curve for safety and success of precut sphincterotomy for therapeutic ERCP: a single endoscopist's experience. Endoscopy 2008; 40: 513-516

107 Fukatsu H, Kawamoto H, Harada R et al. Quantitative assessment of technical proficiency in performing needle-knife precut papillotomy. Surg Endosc 2009; 23: 2066-2072

108 Harewood GC, Baron TH. An assessment of the learning curve for precut biliary sphincterotomy. Am J Gastroenterol 2002; 97: 1708-1712

109 Manes G, Di Giorgio P, Repici A et al. An analysis of the factors associated with the development of complications in patients undergoing precut sphincterotomy: a prospective, controlled, randomized, multicenter study. Am J Gastroenterol 2009; 104: 2412 - 2417

110 de Weerth A, Seitz U, Zhong Y et al. Primary precutting versus conventional over-the-wire sphincterotomy for bile duct access: a prospective randomized study. Endoscopy 2006; 38: 1235 - 1240

111 Tang S-J, Haber GB, Kortan P et al. Precut papillotomy versus persistence in difficult biliary cannulation: a prospective randomized trial. Endoscopy 2005; 37: 58-65

112 Yasuda I, Tomita E, Enya M, Kato T, Moriwaki H. Can endoscopic papillary balloon dilation really preserve sphincter of Oddi function? Gut 2001; 49: 686-691

113 Baron TH, Harewood GC. Endoscopic balloon dilation of the biliary sphincter compared to endoscopic biliary sphincterotomy for removal of common bile duct stones during ERCP: a metaanalysis of randomized, controlled trials. Am J Gastroenterol 2004; 99: 1455 - 1460

114 Weinberg BM, Shindy W, Lo S. Endoscopic balloon sphincter dilation (sphincteroplasty) versus sphincterotomy for common bile duct stones. Cochrane Database Syst Rev 2006; CD004890:

115 DiSario JA, Freeman ML, Bjorkman DJ et al. Endoscopic balloon dilation compared with sphincterotomy for extraction of bile duct stones. Gastroenterology 2004; 127: 1291 - 1299
116 Attasaranya S, Cheon Y, Vittal $H$ et al. Large-diameter biliary orifice balloon dilation to aid in endoscopic bile duct stone removal: a multicenter series. Gastrointest Endosc 2008; 67: 1046-1052

117 Ersoz G, Tekesin O, Ozutemiz AO, Gunsar F. Biliary sphincterotomy plus dilation with a large balloon for bile duct stones that are difficult to extract. Gastrointest Endosc 2003; 57: 156-159

118 Maydeo A, Bhandari S. Balloon sphincteroplasty for removing difficult bile duct stones. Endoscopy 2007; 39: 958 -961

119 Minami A, Hirose S, Nomoto T, Hayakawa S. Small sphincterotomy combined with papillary dilation with large balloon permits retrieval of large stones without mechanical lithotripsy. World J Gastroenterol 2007; 13: $2179-2182$

120 Misra SP, Dwivedi M. Large-diameter balloon dilation after endoscopic sphincterotomy for removal of difficult bile duct stones. Endoscopy 2008; 40: 209-213

$121 \mathrm{Heo} J H$, Kang DH, Jung HJ et al. Endoscopic sphincterotomy plus largeballoon dilation versus endoscopic sphincterotomy for removal of bile-duct stones. Gastrointest Endosc 2007; 66: 720-726; quiz 768, 771

122 Kawamoto M, Geenen J, Omari T et al. Sleeve sphincter of Oddi (SO) manometry: a new method for characterizing the motility of the sphincter of Oddi. J Hepatobiliary Pancreat Surg 2008; 15: 391 - 396

123 Frenz MB, Wehrmann T. Solid state biliary manometry catheter: impact on diagnosis and post-study pancreatitis. Curr Gastroenterol Rep 2007; 9: 171 - 174

124 Craig AG, Omari T, Lingenfelser T et al. Development of a sleeve sensor for measurement of sphincter of Oddi motility. Endoscopy 2001; 33: $651-657$

125 Sherman S, Troiano FP, Hawes RH, Lehman GA. Sphincter of Oddi manometry: decreased risk of clinical pancreatitis with use of a modified aspirating catheter. Gastrointest Endosc 1990; 36: 462 - 466

126 Draganov P, Kowalczyk L, Forsmark C. Prospective trial comparing solid-state catheter and water-perfusion triple-lumen catheter for sphincter of Oddi manometry done at the time of ERCP. Gastrointest Endosc 2009; 70: $92-95$

127 Wehrmann T, Stergiou N, Schmitt T, Dietrich CF, Seifert H. Reduced risk for pancreatitis after endoscopic microtransducer manometry of the sphincter of Oddi: a randomized comparison with the perfusion manometry technique. Endoscopy 2003; 35: 472 - 477

128 Sherman S, Hawes RH, Troiano FP, Lehman GA. Pancreatitis following bile duct sphincter of Oddi manometry: utility of the aspirating catheter. Gastrointest Endosc 1992; 38: 347 - 350

129 Singh $P$, Das A, Isenberg $G$ et al. Does prophylactic pancreatic stent placement reduce the risk of post-ERCP acute pancreatitis? A meta-analysis of controlled trials. Gastrointest Endosc 2004; 60: 544-550

130 Sofuni A, Maguchi H, Itoi T et al. Prophylaxis of post-endoscopic retrograde cholangiopancreatography pancreatitis by an endoscopic pancreatic spontaneous dislodgement stent. Clin Gastroenterol Hepatol 2007; 5: $1339-1346$

131 Chahal $P$, Tarnasky P, Petersen B et al. Short 5Fr vs long 3Fr pancreatic stents in patients at high risk for post- endoscopic cholangiopancreatography pancreatitis. Clin Gastroenterol Hepatol 2009; 7: 834-839

132 Fehmi SMA, Schoenfeld PS, Scheiman JM et al. 5 Fr prophylactic pancreatic stents are easier to place and require fewer guide wires than $3 \mathrm{Fr}$ stents. Gastrointest Endosc 2008; 67: AB328 - AB329

133 Smith MT, Sherman S, Ikenberry SO, Hawes RH, Lehman GA. Alterations in pancreatic ductal morphology following polyethylene pancreatic stent therapy. Gastrointest Endosc 1996; 44: 268-275

134 Das A, Singh P, Sivak MV, Chak A. Pancreatic-stent placement for prevention of post-ERCP pancreatitis: a cost-effectiveness analysis. Gastrointest Endosc 2007; 65: 960 - 968

135 Freeman $M L$, Overby C, Qi D. Pancreatic stent insertion: consequences of failure and results of a modified technique to maximize success. Gastrointest Endosc 2004; 59: 8-14

136 Brackbill S, Young S, Schoenfeld P, Elta G. A survey of physician practices on prophylactic pancreatic stents. Gastrointest Endosc 2006; 64: $45-52$

137 Dumonceau JM, Rigaux J, Kahaleh $M$ et al. Prophylaxis of post-ERCP pancreatitis: a practice survey. Gastrointest Endosc 2010; 71: $934-$ 939 